\title{
An experimental study on the tensile behavior of the cracked aluminum plates repaired by fiber metal laminate (FML) patches
}

\author{
Faramarz Ashenai Ghasemi ${ }^{\mathrm{a}}$, Ahmad Fallah Rahmatabadi, Gholamhassan Payganeh \\ and Ali Pourkamali Anaraki
}

Department of Mechanical Engineering, Shahid Rajaee Teacher Training University (SRTTU), Lavizan, PO Box 36-16785, Tehran, Iran

Received 24 October 2012, Accepted 28 November 2012

\begin{abstract}
Fiber metal laminates (FMLs) are widely used in aerospace industries nowadays. Repairing of the cracks in these advanced materials was first done by some aeronautical laboratories in early 1970s. In this study, experimental investigations were done on the effect of repairing the center-cracked aluminum plates using the FML patches. The repairing processes were conducted to characterize the response of the repaired structures to tensile tests. The composite patches were made of one aluminum layer and two woven glass-epoxy composite layers. Three different crack lengths in three crack angles and different patch lay-ups were examined. It was observed that no matter what the crack length was, the more the crack angle is larger, the more ultimate tensile strength of the structure became. It was also indicated that the patch lay-up had an important effect on the tensile response of the repaired specimens. When the aluminum layer of the patches was farther from the repair zone, the ultimate tensile strength reached to its maximum value.
\end{abstract}

Key words: Fiber metal laminate (FML) / repair / tensile strength / crack

\section{Introduction}

Fibre-metal laminates (FMLs) are hybrid structures based on thin metal sheets and of fibre-reinforced polymer (FRP) plies. These hybrid material systems combine the excellent specific strength, and fatigue properties of composites and the machinability and toughness of metals [1]. They were initially developed at the National Aerospace Laboratory in Netherlands, after fatigue studies on the centre wings of a Fokker F-27 showed that bonded metal laminates presented promising fatigue properties. Subsequent enhancement of their mechanical properties at the Technological Delft University resulted into commercially available FMLs under the trade name of ARALL (aramid fibre/aluminum) and GLARE (glass fibre/aluminum) [2]. Current applications of FMLs include fuselages, leading edges, etc. in the Airbus A380, where weight reduction and improved damage tolerance ability are critical [3].

One of the serious shortcomings of the currentgeneration of FMLs is that they have a low Young's modulus because woven glass-fabrics have fairly low tensile modulus. As a result, the modulus of glass/epoxy composite layer is low, nearly $26 \mathrm{GPa}$, which is lower than

\footnotetext{
a Corresponding author:

Faramarz_ashenai_ghasemi@yahoo.com
}

that of the aluminum layer. Nevertheless, woven glassfabric used in the current generation of the FMLs has a high tensile strength and strain-to-failure. The combination of lower modulus of glass/epoxy layers and aluminum layer inevitably produces a laminate with a Young's modulus lower than that of the monolithic aluminum alloy [4]. This may limit the applications of the FMLs in aircraft structures where the stiffness is a predominant design requirement.

The lower modulus of glass/epoxy composite layers also leads to another serious concern, that is, the load carried by the aluminum layers is proportionally higher due to its higher modulus than the composite layers. The presence of high stress leads to a shorter fatigue crack initiation life of the aluminum layer [5-7]. In order to reduce the stress concentration and to improve the fatigue crack initiation life in the aluminum layer, it is necessary to increase the modulus of the composite layer. The beneficial effect of mixing boron and glass fiber layers on improving the Young's modulus and the yield strength in the hybrid boron/glass/aluminum FMLs has been successfully demonstrated in [8].

In this paper, the tensile behavior of the cracked aluminum plates repaired with FML patches was studied by changing three factors i.e. crack length, crack angle and 
the lay-up of FMLs. The aluminum plates were made of AA1035 and the FML patches made of woven glass-fabric $\left(T\left(90^{\circ}\right) / \mathrm{M} 200-\mathrm{E} 10\right)$ layer as the fiber layers, and one thin aluminum sheet (AA1035, $0.3 \mathrm{~mm}$ ) as the metal layer. The results were discussed and the effects of the desired factors were clarified on improving the ultimate tensile strength of the aluminum cracked specimens repaired by the FML patches.

\section{Specimens and patches preparation}

\subsection{Cracked aluminum plates}

In this study, the specimens were made of aluminum plate AA1035 having dimensions [9] as shown in Figures 1 and 2. The mechanical properties of aluminum plate were indicated by tensile tests and are given in Figure 3 and Table 1 . The specimens were cut with a HYDRAjet water jet machine in principle dimensions and thereafter, using a wire cut machine. The notch length to the specimen width ratio was chosen as $a / w=0.3,0.4$ and $0.5 \mathrm{~m}$ where, " $a$ " is the crack length and " $w$ " is the specimen width. The notches were created on center of the specimens. The crack width was $0.25 \mathrm{~mm}$ and the crack angle with respect to the width axis of specimen have three angle states, as $0^{\circ}, 30^{\circ}$ and $45^{\circ}$. The cracks were prepared on the condition that the specimens with the same crack configurations in length and angle were kept together and then wire cut.

In order to have a complete bonding between the specimens and FML patches the surface preparation procedure according to the P2 etching process [10] was conducted on the bonding surface of the aluminum specimens. In this method the bonding surface of the aluminum plate was degreased with acetone at first, and then abraded with emery cloth. Thereafter alkaline cleaning was applied, and then the specimens were immersed for 12 min at $65-70{ }^{\circ} \mathrm{C}$ P2etch mixture of $15 \%$ by weight FeSo $4,37 \% \mathrm{H}_{2} \mathrm{So}_{4}$ and $48 \%$ water, and then washed with the clean cold running water, followed by clean hot water and dried with hot air. The temperature of the hot water and air must not be greater than $65^{\circ} \mathrm{C}$ [11].

\subsection{FML patches}

The FML composite patch was fabricated with two woven glass-fabric $\left(\mathrm{T}\left(90^{\circ}\right) / \mathrm{M} 200-\mathrm{E} 10\right)$ layers as the fiber layers (GFRP), and one thin aluminum sheet (AA1035, $0.3 \mathrm{~mm}$ ) as the metal layer. For strong bonding between fiber (F) layers and aluminum (A) layers in the patch layup the surface preparation procedure for bonding surfaces of metal layer was done according to the standard [12]. The lay-up of the FML patch varies in different lay-ups so that the metal layer can be near of or far from the repair surface. Three different repair types with respect to the patch lay-up were conducted on cracked specimens. In first repaired types the lay-up of the patches was F-FA from bottom to up. In second repaired ones the lay-up

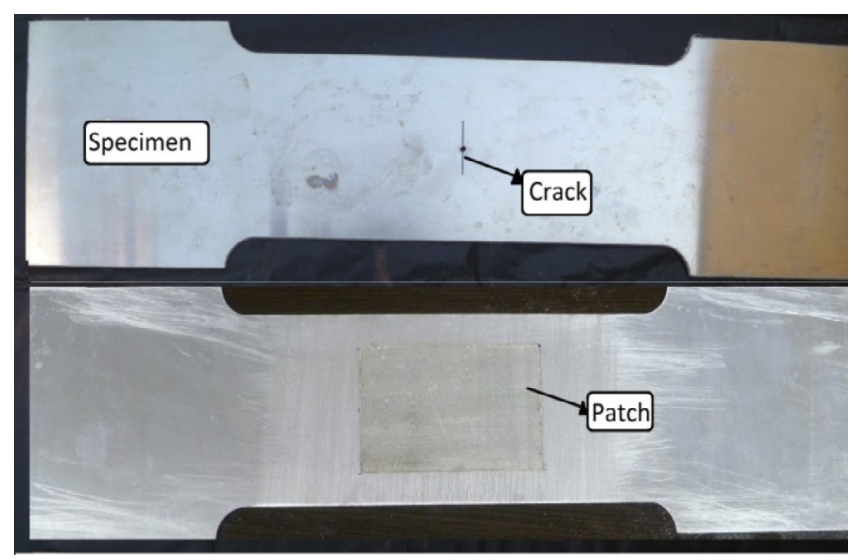

Fig. 1. (a) Unpatched-cracked and (b) patched-cracked specimens.

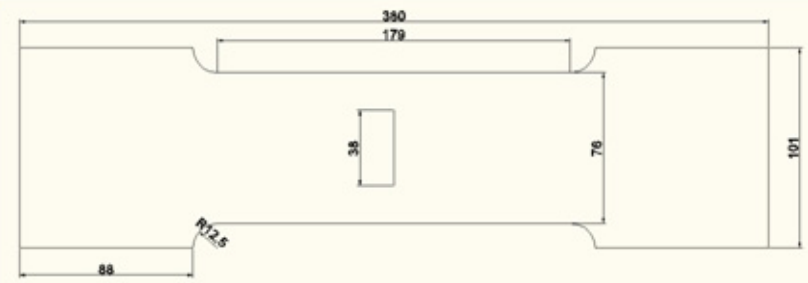

Fig. 2. Specifications of an unpatched aluminum specimen (all dimensions are in $\mathrm{mm}$ ).

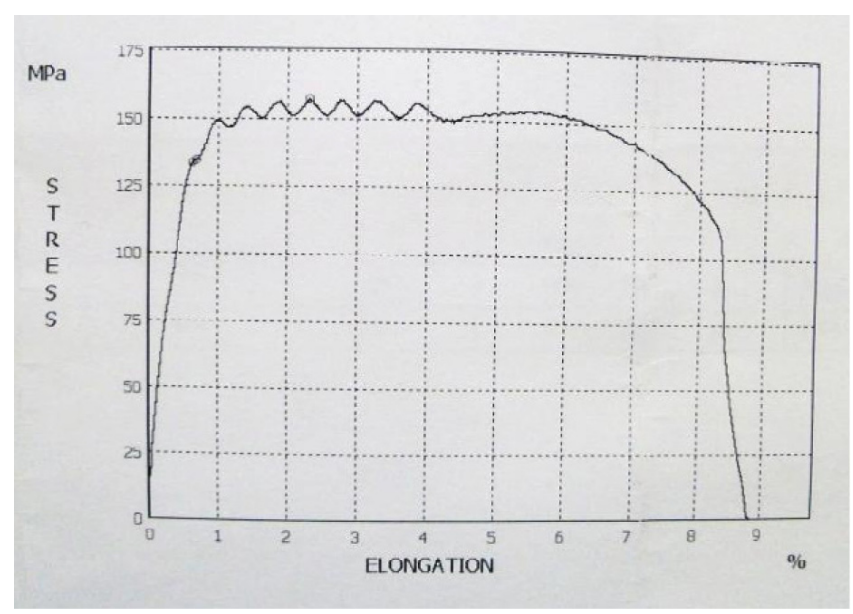

Fig. 3. Stress-strain curve for aluminum plates.

was F-A-F, and finally the patch lay-up was A-F-F. For matrix, epoxy (LY5052) was used because of its efficiency for the aerospace applications. The content of fiber was about $55 \%$ by weight in glass-epoxy layers. The composite lay-up was made by hand and then the curing procedure according to the recommended cure schedule in two stages was done [13]. At first the patches were cured in $60^{\circ} \mathrm{C}$ for $2 \mathrm{~h}$ and then in $80^{\circ} \mathrm{C}$ for $4 \mathrm{~h}$. The patches had dimensions of $80 \mathrm{~mm} \times 50 \mathrm{~mm}$ and after curing the thickness of the patches was reached to about $0.7 \mathrm{~mm}$. Table 1 shows the 
Table 1. Mechanical properties of specimens and patches.

\begin{tabular}{cccccc}
\hline & Young's modulus & Shear modulus & Ultimate tensile strength & Density & Poisson's ratio \\
\cline { 2 - 6 } & $E_{1}=E_{2}(\mathrm{GPa})$ & $\mathrm{G}(\mathrm{GPa} / \mathrm{MPa})$ & $S_{1}=S_{2}(\mathrm{MPa})$ & $\rho$ (g.cm $\left.^{-3}\right)$ & $\nu$ \\
\hline Aluminum AA1035 & 69 & $26(\mathrm{Gpa})$ & 167 & 2.7 & 0.3 \\
Epoxy-LY5052 & 3.5 & - & 60 & 1.16 & 0.35 \\
GFRP layer & 26 & - & 230 & 1.6 & 0.25 \\
Araldite-2015 & 2 & $10-20 \mathrm{MPa}$ & 30 & 1.4 & - \\
\hline
\end{tabular}

Table 2. Arrangement of the experiments.

\begin{tabular}{cccc}
\hline Trials & Crack angle & Crack length $(a / w)$ & Patch lay-up \\
\hline 1 & $0^{\circ}$ & 0.3 & F-F-AL \\
2 & $0^{\circ}$ & 0.3 & F-AL-F \\
3 & $0^{\circ}$ & 0.3 & NO patch \\
4 & $45^{\circ}$ & 0.3 & F-F-AL \\
5 & $45^{\circ}$ & 0.3 & F-AL-F \\
6 & $45^{\circ}$ & 0.3 & No patch \\
7 & $30^{\circ}$ & 0.4 & AL-F-F \\
8 & $30^{\circ}$ & 0.4 & No patch \\
9 & $0^{\circ}$ & 0.5 & F-F-AL \\
10 & 00 & 0.5 & F-AL-F \\
11 & $0^{\circ}$ & 0.5 & No patch \\
12 & $45^{\circ}$ & 0.5 & F-F-AL \\
13 & $45^{\circ}$ & 0.5 & F-AL-F \\
14 & $45^{\circ}$ & 0.5 & No patch \\
\hline
\end{tabular}

mechanical properties of patches as well as the bonding material.

The adhesive Araldite 2015 was used for bonding the FML patches to the cracked plates. The thickness of the adhesive layer was about $0.2 \mathrm{~mm}$. For bonding the metal layer of the patches to the specimens, surface preparation procedure was done according to the P2 etching process. For bonding the FRP layer, the surface preparation was done according to the procedure recommended for thermoset materials [13].

In this study, three factors are studied, crack length, crack angle and the lay-up of FML patches. Table 2 shows the experiments that should be conducted on the repaired specimens. To compare the results, the ratio of ultimate strength of the repaired specimens to the unrepaired ones should be obtained. Therefore, fourteen experiments must be done.

\section{Tensile tests}

After the specimens' preparation, some experimental tests were performed. Tensile tests were conducted on specimens on the Instron 8802 tension-testing machine [14] (Fig. 4), which has a maximum load capacity of $250 \mathrm{kN}$ (25 Ton). The specimens were loaded in tension at a rate of $2 \mathrm{~mm} \cdot \mathrm{min}^{-1}$ up to failure. The data of the tests were acquired and stored into a computer and were later plotted as a load-displacement curve. Figures 5-9 show the tensile tests results of patched and unpatched specimens. It was found that the Young's modulus of patched specimens with different crack lengths and angles was nearly equal.

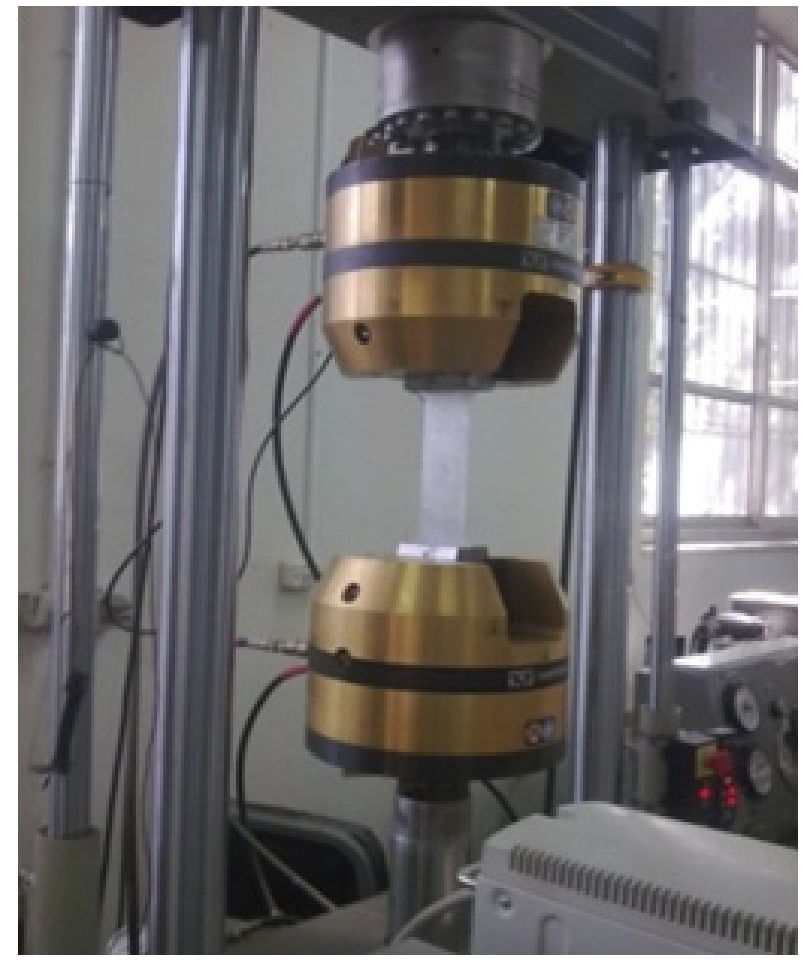

Fig. 4. Specimen positioning for tensile test by the Instron 8802 tension-testing machine.

\section{Results and discussions}

Due to the brittle behavior of cracked specimens (repaired and unrepaired), their ultimate tensile strength is 


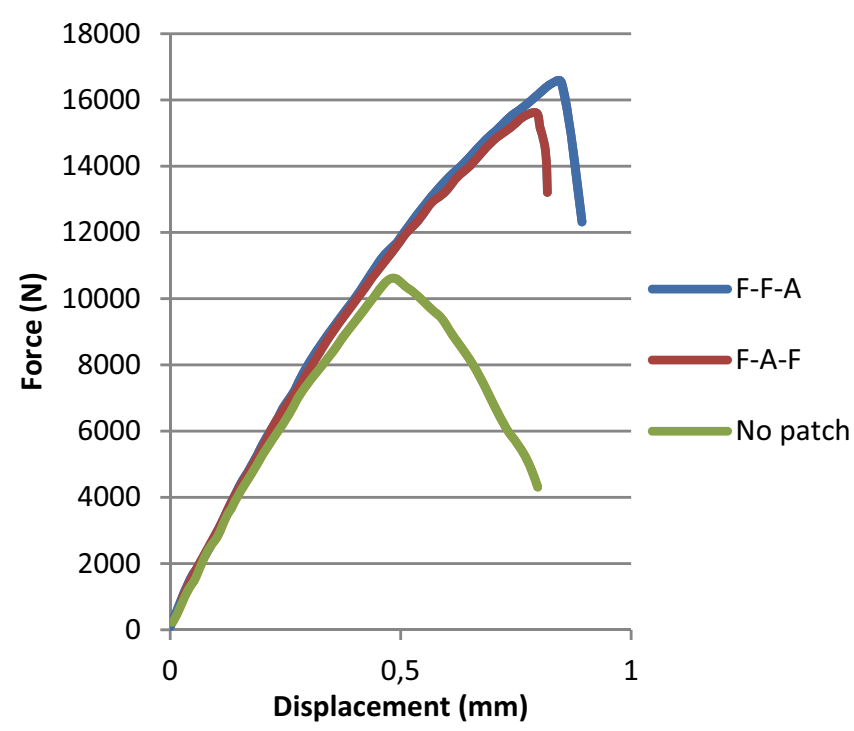

Fig. 5. Comparison of load-displacement curves for specimens with $a / w=0.3, \theta=0^{\circ}$.

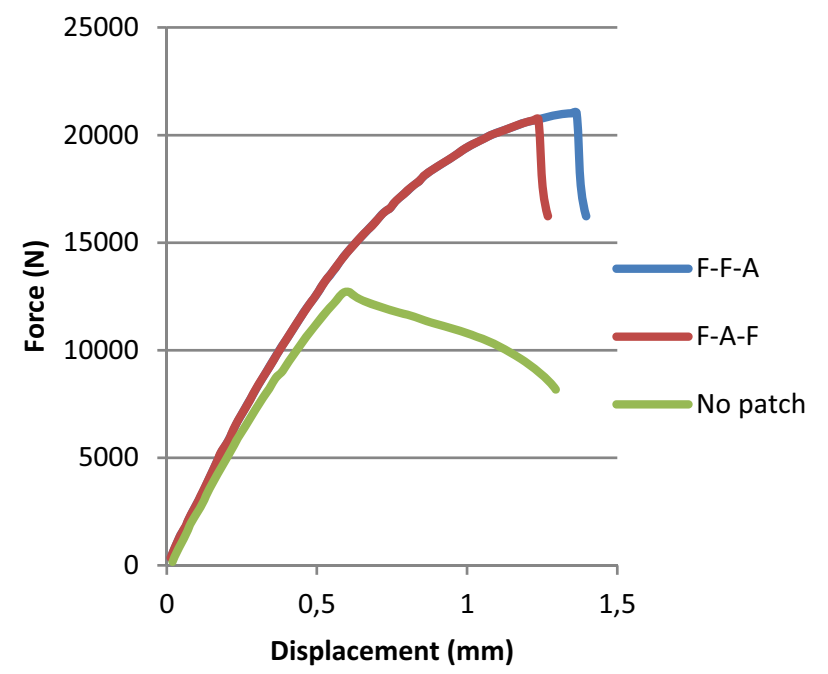

Fig. 6. Comparison of load-displacement curves for specimens with $a / w=0.3, \theta=45^{\circ}$.

studied. The ratio of ultimate tensile strength of the repaired to the unrepaired specimens is also calculated. In order to better uptake of results, the results are departed into three parts that each part explains the effect of each factor on the ultimate strength of specimens. It must be noted that in all of the tests, no separation was seen between plate and the patch or between the FML layers. While in the Chukwujekwu Okafor et al. research [15], some separations were seen. This shows the good efficiency of the adhesive and also well surface preparation done in the present condition.

\subsection{The effect of crack angles and lengths}

At first, the unpatched cracked specimens were tested. The results of these tests are depicted in Table 3. A

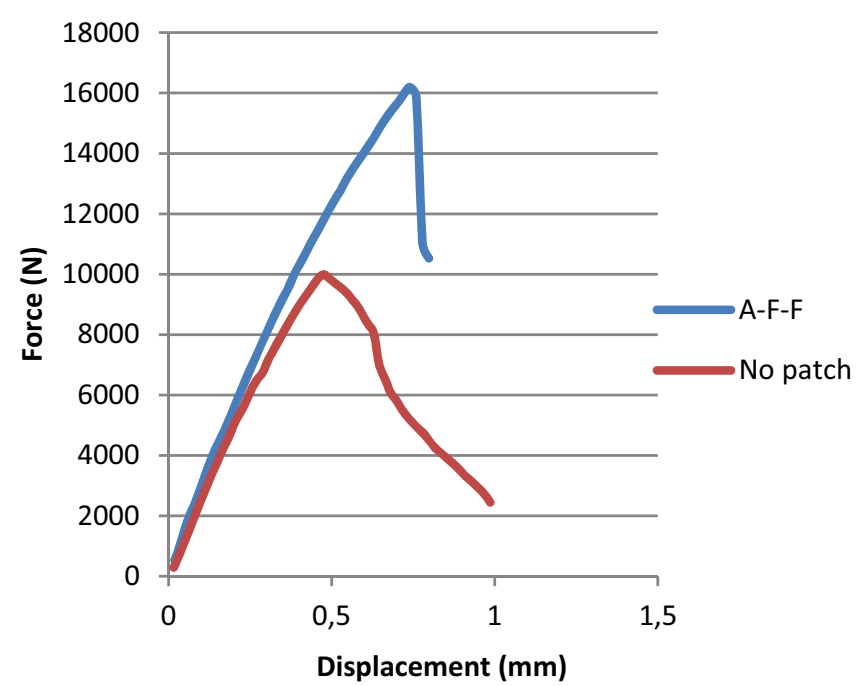

Fig. 7. Comparison of load-displacement curves for specimens with $a / w=0.4, \theta=30^{\circ}$.

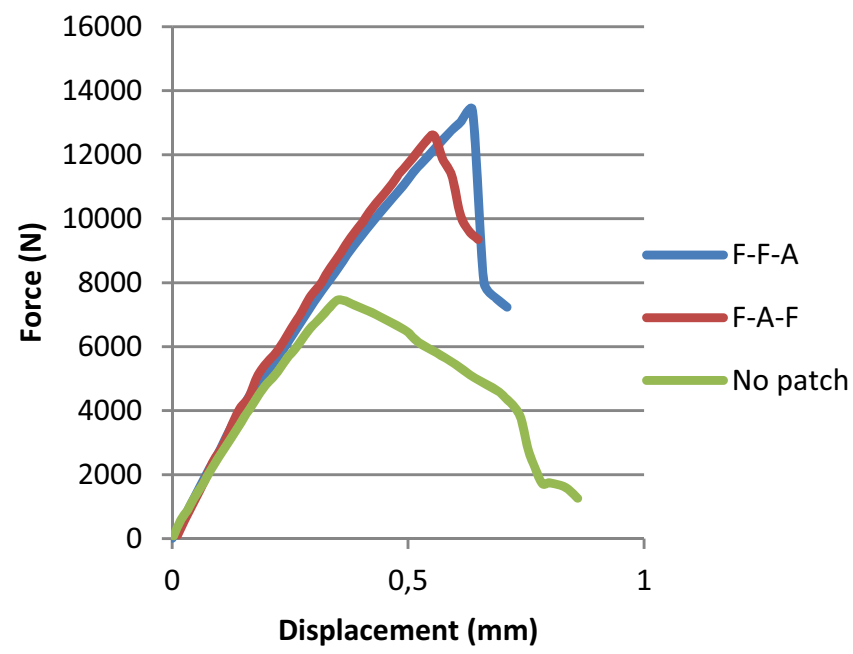

Fig. 8. Comparison of load-displacement curves for specimens with $a / w=0.5, \theta=0^{\circ}$.

positive increase of the ultimate (maximum) load of the specimens is seen by increasing the crack angle no matter what the crack length is. This is because of changing the crack growth path that forces the crack to go in mode I of the fracture. This change in direction leads to a more energy absorption too.

Figure 10 shows that by increasing of the crack angle, the ultimate tensile strength of the repaired specimens increases. For example, when $a / w=0.3$ and F-F-A patch is used, by increasing the crack angle from $0^{\circ}$ to $45^{\circ}$ there would be an increase about 27 percent in the ultimate tensile strength of the specimens. It's because of changing the growth path of crack during the loading time, which forces it to be in the direction that crack goes to mode I of the fracture. This change leads to an increase in tensile strength of the structure (Fig. 10).

It is obvious that the more the crack length is, the less the ultimate tensile strength of the structure becomes. 
Table 3. Ultimate (maximum) load (N) of unrepaired specimens.

\begin{tabular}{cccc}
\hline \multirow{2}{*}{ Crack angle } & \multicolumn{4}{c}{ Ultimate (maximum) load $(\mathrm{N})$ for different crack lengths $(a / w)$} \\
\cline { 2 - 4 } & $a / w=0.3$ & $a / w=0.4$ & $a / w=0.5$ \\
\hline $0^{\circ}$ & 10688 & - & 7474 \\
$30^{\circ}$ & - & 9998 & - \\
$45^{\circ}$ & 12722 & - & 9761 \\
\hline
\end{tabular}

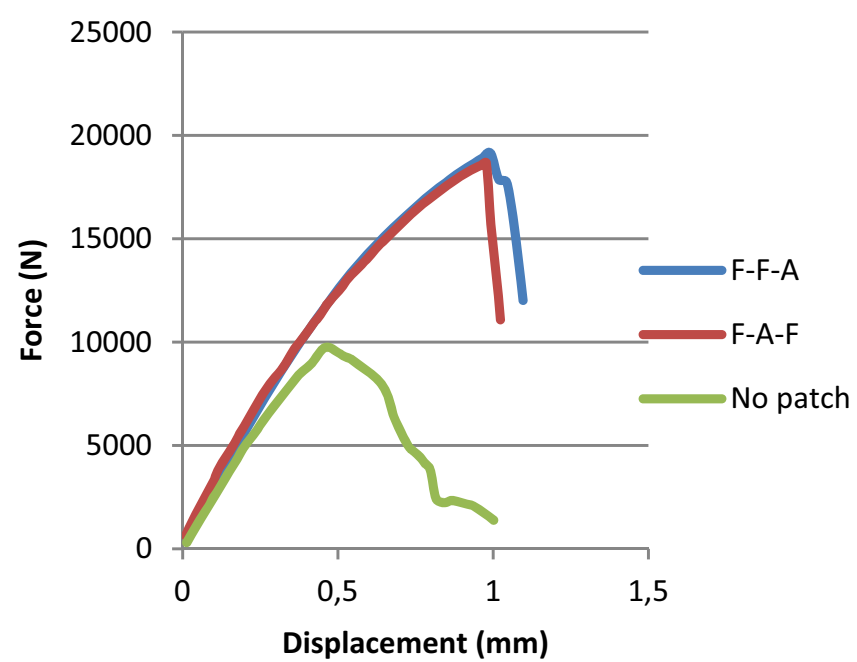

Fig. 9. Comparison of load-displacement curves for specimens with $a / w=0.5, \theta=45^{\circ}$.

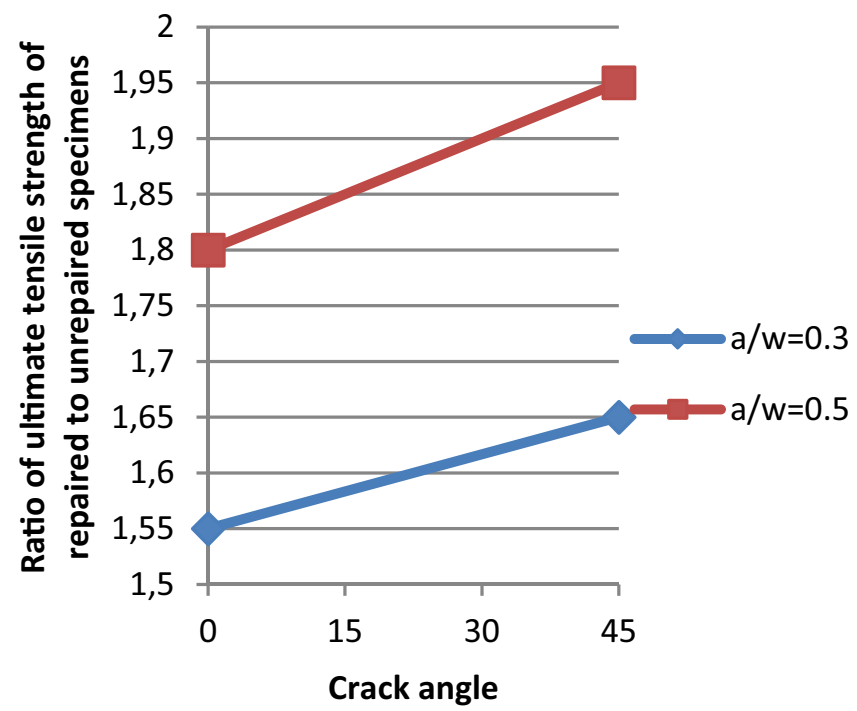

Fig. 10. Ratio of the ultimate tensile strength of the repaired to unrepaired specimens with different crack angles and repaired by F-F-A patch type.

But, the more the crack length is, the effects of the patches on the ultimate tensile strength of specimens become more (Fig. 11). For example, when the crack angle is $0^{\circ}$ and the patch has a lay-up type as F-A-F and $a / w=0.3$, the amount of increasing of the ultimate tensile strength of the repaired to the unrepaired specimens is about $48 \%$,

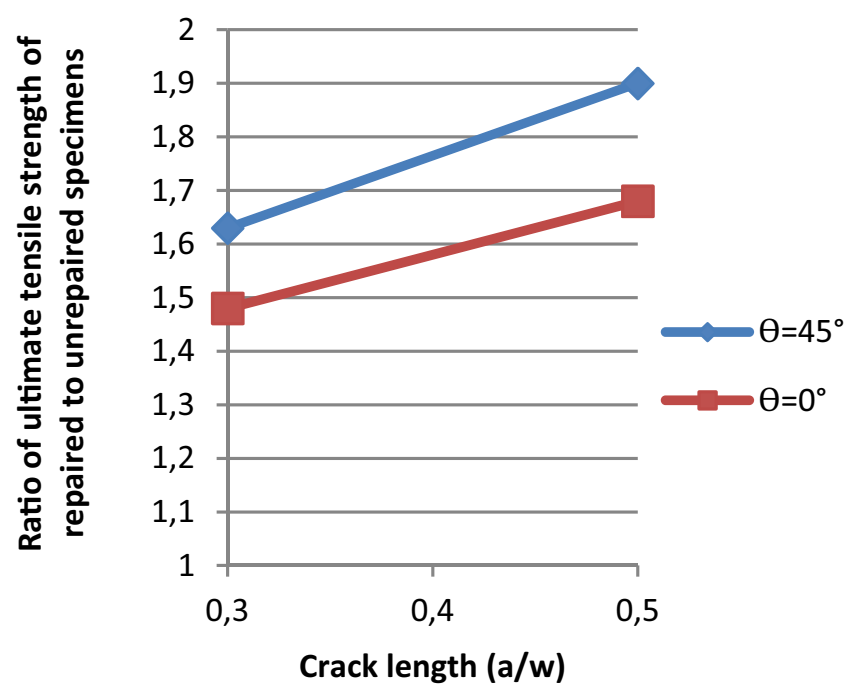

Fig. 11. Ratio of the ultimate tensile strength of the repaired to unrepaired specimens with different crack angles and repaired by F-A-F patch type.

while if $a / w=0.5$ this value becomes $68 \%$. By increasing of the crack length, the path that crack must pass to reach to mode I of fracture becomes longer and the amount of ultimate tensile strength increases too.

\subsection{The effect of FML patch lay-ups}

Figure 12 shows that the effect of F-F-A patch type is more than the other ones. This is because the repair is asymmetrical. Therefore, a bending moment is produced during the tensile test. This makes the structure to bend towards the patch and the crack tends to open from the opposite side of the repair very quickly. Therefore, if the patches act in a way that prevents the structure to bend, the specimens fail later. Whenever aluminum layer of the patch is bonded to the repair surface, the ductility of the whole structure becomes more. Therefore, the patch could be able to absorb the more energy by plasticity of the metal layer. When it is in the middle of patch lay-up or even more far from repair surface, the brittle fracture occurs. This is because that FRP layer has less ductility and when this layer breaks, the aluminum layer of the patch breaks suddenly too.

Also, the A-F-F patch type is more effective than the F-A-F type. Therefore, if the aluminum layer is located in the farthest point from the surface of repair, the ultimate 


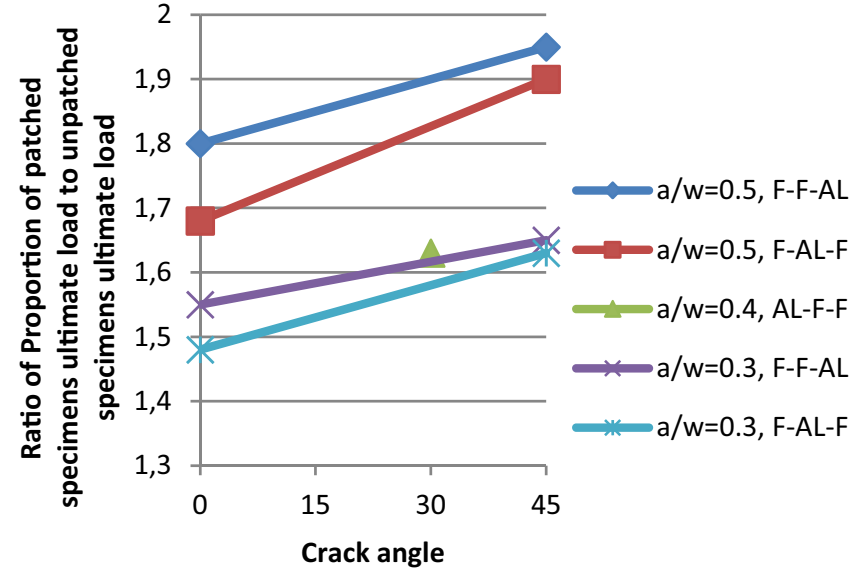

Fig. 12. Ratio of the ultimate tensile strength of the repaired to unrepaired specimens with different crack angles.

tensile strength of the structure becomes the most. This is because when the aluminum layer of patch is far from the repair surface, due to high stiffness of the aluminum, the stiffness of the patch against the bending increases. Therefore, the structure will bend less and the ultimate tensile strength of the structure increases. Now, it can be understood that why and how the location of the metal layer in the patch lay-up is effective upon the efficiency of the repair.

\section{Conclusions}

In order to see the effect of repairing of the centercracked aluminum specimens, using of FML patches, the specimens were subjected to tensile tests. The following results were found:

1. The more the crack angle is (in a constant crack length), the less increase results in the amount of ultimate tensile strength of the repaired specimens.

2. Tensile strength of repaired and unrepaired specimens will be decreased by increasing of the crack length.

3. No matter what the crack characteristics are, the strength of the repaired structures depends on type of the patch lay-ups.

4. The amount of the ultimate tensile strength of the repaired structures with $a / w=0.3$ and $\theta=0^{\circ}$ and $\mathrm{F}$ F-A patch layup respect to the same unpatched ones is equal to 1.55 .

\section{References}

[1] R.Y. Qin, H.P. Schreiber, Adhesion at partially restructured polymer surfaces, Colloids Surf. A: Physicochem, Eng. Aspects 156 (1999) 85-93

[2] R.C. Alderliesten, Fatigue, In Fibre metal laminates: an introduction, ed. A. Vlot, J.W. Gunnink, Kluwer Academic Publishers, Dordrecht, 2001, pp. 155-171

[3] Guocai Wu, Jenn-Ming Yang, The mechanical behaviour of GLARE laminates for aircraft structures, J. Minerals Mater. Soc. 57 (2005) 72-79

[4] M. Hagenbeek, C. Van Hengel, O.J. Bosker, C.A.J.R. Vermeeren, Static properties of fibre metal laminates, Appl. Compos. Mater. 10 (2003) 207-222

[5] J.J. Homan, Fatigue initiation in fibre metal laminates, Int. J. Fatigue 28 (2006) 366-374

[6] Po-Yu Chang, Jenn-Ming Yang, Hyoung-seock Seo, H.T. Hahn, Off-axis fatigue cracking behavior in notched fiber metal laminates, Fatigue Fracture Eng. Mater. Struct. 30 (2007) 1158-1171

[7] Po-Yu Chang, Po-Ching Yeh, Jenn-Ming Yang, Static behavior of notched and un-notched fiber metal laminates with hybrid boron/glass fibers, Modeling and Simulation in Materials Science and Engineering, 2008, submitted

[8] H.M. Clearfield, D.K. McNamara, G.D. Davis, In Engineered materials handbook, Adhesives and sealants, ed. H.F. Brinson, ASM Inter. 3 (1990) 260

[9] H. Hosseini-Toudeshky, B. Mohammadi, S. Bakhshandeh, Crack trajectory analysis of single-side repaired thin panels in mixed-mode conditions using glass/epoxy patches, Comp. Struct. 86 (2008) 997-1005

[10] ASTM D 2651, American Society for Testing and Materials (ASTM), West Consnohocken, USA, 1995 Standard guide for preparation of metal surfaces for adhesive bonding

[11] Huntsman Advanced materials data sheet for Araldite LY5052-1 /Aradure 5052-1, www.huntsman.com/ advanced_materials, 2007

[12] Advanced materials data sheet for Araldite 2015, www. huntsman.com/advanced_materials, April 2007

[13] R.F. Wegman, Surface preparation techniques for adhesive bonding. William Andrew Inc. Noyes Publication, 1989

[14] www.instron.com

[15] A. Chukwujekwu Okafor, N. Singh, U.E. Enemuoh, S.V. Rao, Design, analysis and performance of adhesively bonded composite patch repair of cracked aluminum aircraft panels, Compos. Struct. 71 (2005) 258-270 